\title{
Investigation of Influence of Surface Roughness on Pitting Corrosion of Duplex Stainless Steel 2205 using Various Electrochemical Techniques
}

\author{
Yiwei Tang, Nianwei Dai, Jun Wu, Yiming Jiang, Jin Li * \\ Department of Material Science, Fudan University, Shanghai, China \\ *E-mail: corrosion@fudan.edu.cn
}

doi: $10.20964 / 2019.07 .51$

Received: 8 March 2019 / Accepted: 26 April 2019 / Published: 10 June 2019

\begin{abstract}
The metastable and stable pitting behaviors on different surface roughness finishes for DSS 2205 stainless steel have been investigated. Surface roughness was analyzed through the adoption of atomic force microscopy (AFM). Pitting corrosion susceptibility of duplex stainless steel (DSS) 2205 in sodium chloride solution was evaluated by means of critical pitting temperature (CPT), potentiodynamic polarization, electrochemical impedance spectroscopy (EIS) and potentiostatic measurement. The statistical analysis revealed that the smoother surface of DSS 2205 exhibited lower pitting corrosion susceptibility and better corrosion resistance. Based on the surface analysis, depth-width ratio was introduced as a parameter to present surface roughness and was used in the characterization of the relationship between surface roughness and pitting corrosion.
\end{abstract}

Keywords: Pitting corrosion, Surface roughness, Electrochemical technique, Duplex stainless steel, Depth-width ratio

\section{$\underline{\text { FULL TEXT }}$}

(C) 2019 The Authors. Published by ESG (www.electrochemsci.org). This article is an open access article distributed under the terms and conditions of the Creative Commons Attribution license (http://creativecommons.org/licenses/by/4.0/). 